\title{
Correlation Between Parent's Education Level and Frequency of Therapy with The Quality of Life in Children with Cerebral Palsy
}

\author{
Sylvia Evelyn Aritonang, Marietta Shanti Prananta, Marina A. Moeliono
}

Departement of Physical Medicine and Rehabilitation., University of Padjadjaran / Hasan Sadikin General Hospital, Bandung, Indonesia.

\begin{abstract}
Introduction : Cerebral Palsy $(\mathrm{CP})$ is the most frequent cause of disability in children, $\mathrm{CP}$ has high risk to have lower quality of life (QoL). There were several factors may have a relationship with quality of life (QoL) of children with CP. The aim is to determine the correlation of QOL of patients with Cerebral Palsy.
\end{abstract}

Methods this study was a cross-sectional study, 60 subjects, children with CP aged 2-12 y.o divided into three groups depend on age;2-4, 5-7, and 6-12 years old. The subjects' QoL was measured using Pediatric Scale Quality of Life (PedsQoL)

Results: Study of 60 children with CP consisted $38(63,3 \%)$ of male, were divided in three groups of age, respectively; 2-4 y.o; 12(20\%), 5-7 y.o; 13 (21,7\%), 8-12 y.o; 13(21,7\%). Father's and mother's education level were primary school, junior, and senior high school respectively; $18(30 \%)$ and $18(30 \%), 9(15 \%)$ and 22(37\%), $33(55 \%)$ and $20(33 \%)$. Frequency of therapy were less than 4 times/week was 31(51,7\%), and 4 times/week was 29 (28,3\%). There were a strong positive correlation between father's and mother's education level with PedsQoL; $(r=0,67 ; p=0,00)$ and $(r=0,70 ; p=0,00)$, as well as between the frequency of therapy with PedsQoL; $(\mathrm{r}=0,69 ; \mathrm{p}=0,00)$.

Conclusion: Higher mother's and father's education level have correlation with higher PedsQoL,

Keyword: cerebral palsy, pediatric quality of life, parent's education level, frequency of therapy

\section{Correspondent Detail:}

Sylvia Evelyn Aritonang

Email: syl_everland@yahoo.com

Departement of Physical Medicine and Rehabilitation,

University of Padjdjaran Bandung, Indonesia 


\section{INTRODUCTION}

Cerebral Palsy (CP) is the most frequent cause of disability in children. ${ }^{1}$ Prevalence of $\mathrm{CP}$ was reportedly $2-2.5$ per 1000 live births. ${ }^{2}$ Cerebral palsy is a disorder of movement, muscle tone or posture that is caused by damaged that occurs to the immature, developing brain. Those disorder could increase dependency on selfcare, daily activities and should be a significant problem for patients, families, and health professionals. The disability in children with $\mathrm{CP}$ will reduce the quality of life (QoL). The role of parent is the most important in children with CP development, so parent's education level may affect the QoL of children with CP. In other hand, specific rehabilitation programs should be done to optimize functions related to selfcare and daily activities. Inadequate management of children with $\mathrm{CP}$ may delay the development of the functions. Studies found that the earlier detected and appropriate rehabilitation management started on children with CP will achieved the better QoL. Adequate rehabilitation program may be related with frequency of therapy. The more frequency of therapy suggested applied, the more effective the therapy will be.

Quality of life is a concept of life which includes aspects such as physical, mental, social, and emotional characteristics. ${ }^{6}$ Definition of QoL by WHO is an "individuals' perception towards their position in life in the context of the culture and value system, in which they live and in relation to their goals, expectations, standards, and concerns". ${ }^{7}$ There are several factors which presumably may affect QoL in children with $\mathrm{CP}$, i.e., parent's education, and the frequency of therapy.

Quality of life was measured by using several instruments. ${ }^{6,7}$ Among QoL measurement instruments, the pediatric quality of life inventory (PedsQoL) is considered to be most valid and reliable. This has not been validated in Indonesia. Many factors influence the quality of life related to QoL in children, particularly with CP, should be studied extensively, to direct the most effective rehabilitation program for each patient.

This study aimed to describe QoL of children with $\mathrm{CP}$ aged 2-12 y.o., and to analyze the correlation between parents' education level and frequency of therapy with QoL of children with CP.

\section{METHODS}

This study was a cross-sectional study, conducted in outpatient of Dr. Hasan Sadikin General Hospital, Bandung and Yayasan Penyandang Anak Cacat (Foundation for Disabled Children) in Bandung, Indonesia. The sampling recruited by consecutive random sampling. Total samples were 60 children with CP. The subjects were classified into three groups depending on their age; $2-4,5-7$, and 8-12 years old, each consisted 20 subjects. The subject's parents were given information relating to the study and willing to sign the 
informed consent. The exclusion criterion was having any illness requiring hospitalization in the last one month.

\section{RESULTS}

\section{Clinical characteristic of subjects}

The subjects' characteristics were shown in table 1 . The data showed that the number of males with $\mathrm{CP}$ was higher. The study population consisted of $36.7 \%(n=22)$ females and $63.3 \%$ $(n=38)$ males children with cerebral palsy. Their groups depending on their age; $2-4$ males $20 \%(n=12)$, females $13,3 \%(n=8), 5-7$ years males $21,7 \%(\mathrm{n}=13)$, females $11,7 \%(\mathrm{n}=7)$, and 8-12 years old, males $21,7 \%(\mathrm{n}=13)$, females $11,7 \%(n=7)$.

Table 1. Clinical characteristic of subjects

\begin{tabular}{ccc} 
Age Groups & \multicolumn{1}{c}{ Males } & Female \\
\hline $2-4$ years & $12(20 \%)$ & $8(13,3 \%)$ \\
$5-7$ years & $13(21,7 \%)$ & $7(11,7 \%)$ \\
$8-12$ years & $13(21,7 \%)$ & $7(11,7 \%)$ \\
& $38(63,3 \%)$ & $22(36,7 \%)$ \\
\hline
\end{tabular}

Parents' education level were shown in table 2. The education ranged from primary school to senior high school. The data are revealing that most of the parents were senior high school graduates, i.e., father was $33(55 \%)$, and mother was $20(33 \%)$
Table 2. Parents' education level

\begin{tabular}{|c|c|c|c|c|c|c|}
\hline \multirow[b]{2}{*}{$\begin{array}{l}\text { Age } \\
\text { Groups }\end{array}$} & \multicolumn{3}{|c|}{ Fathers' Education Level M } & \multicolumn{3}{|c|}{ others' Education Level } \\
\hline & $\begin{array}{l}\text { Primary } \\
\text { School }\end{array}$ & $\begin{array}{c}\text { Junior } \\
\text { High } \\
\text { School } \\
\end{array}$ & $\begin{array}{c}\text { Senior } \\
\text { High } \\
\text { School }\end{array}$ & $\begin{array}{c}\text { Primary } \\
\text { School }\end{array}$ & $\begin{array}{c}\text { Junior } \\
\text { High } \\
\text { School } \\
\end{array}$ & $\begin{array}{c}\text { Senior } \\
\text { High } \\
\text { School }\end{array}$ \\
\hline $2-4$ years & 9 & 1 & 109 & 5 & 6 & \\
\hline $5-7$ years & 4 & 4 & 124 & 8 & 8 & \\
\hline $\begin{array}{l}8-12 \\
\text { years }\end{array}$ & 5 & 4 & 115 & 9 & 6 & \\
\hline Total & $18(30 \%) 9$ & $(15 \%)$ & $33(55 \%)$ & $18(30 \%)$ & $22(37 \%)$ & $20(33 \%)$ \\
\hline
\end{tabular}

The frequency of therapy in Table 3 showed most subject had done therapy less than 4 times/week 31(51,7\%), and most of the subjects showed poor QoL. This study found the minimal to maximal PedsQoL scored was 36.4 to 72.3 , and the mean was $56,9 \pm 9,02$.

Table 3. The Frequency of Therapy and The Data of PedsQoL

\begin{tabular}{cc}
\hline & n (\%) \\
\hline Frequency of Therapy & \\
$<4 \mathrm{x}$ & $31(51.7)$ \\
$4 \mathrm{x}$ & $29(48.3)$ \\
$>4 \mathrm{x}$ & $0(0)$ \\
& \\
The Data of PedsQoL & $56.93 \pm 9,02$ \\
Average of & 36,4 \\
Minimum & 72,3 \\
Maximum &
\end{tabular}

Correlation between parent's education level and Frequency of therapy with Peds Qol in Table 4 showed the positive correlation between the fathers' and mothers' education level with PedsQoL $(r=0,67 ; p=0,00)$ and $(r=0,70 ; p=0,00)$ , as well as between frequen 
Table 4. Correlation between

Parent's Education Level and Frequency of Therapy with PedsQoL

\begin{tabular}{lcc} 
& $\mathrm{r}$ & $\mathrm{p}$ Value \\
\hline Fathers' education level & 0.67 & $0.000^{*}$ \\
Mothers' education level & 0.70 & $0.000^{*}$ \\
Therapy frequency per month & 0.69 & $0.000^{*}$ \\
\hline *Spearman-rho test & &
\end{tabular}

\section{DISCUSSION}

Data in Table 1 was supported a previous study by Cauleen Boyle in the United States that CP prevalence in males was higher group than females. ${ }^{8}$ Data for parents' education level showed that most of the fathers had passed from senior high school (55\%), while almost all mothers had passed from junior high school $(36.7 \%)$. Analysis study showed the correlation between the parents' education level with PedsQoL. This result supported the previous study has proved that knowledge of the parents is essential relating to QoL of children with CP. ${ }^{17}$ Higher parents' education level may has higher socioeconomic status. Study by Glinac in Bosnia, which found that socioeconomic status influences QoL of children with CP. Good socioeconomic status will increase the opportunity to bring children to seek the medical professional, as well as has the funds for the treatment . ${ }^{10}$ The previous study suggested that physical and financial aspects can influence access to healthcare as well. ${ }^{12,13}$ There was a correlation between access to rehabilitation care and QoL of disabled children. ${ }^{14}$ Accessibility to healthcare will affect the therapy frequency of children with $\mathrm{CP}{ }^{16}$ Based on study results presumably that higher parents' education have more opportunity to have higher socioeconomic status, and accessibility to reach healthcare facility. In other hand, Tessier found that there is the correlation between the number of comorbidities of children with $\mathrm{CP}$ and QoL. ${ }^{17}$ This result proved that the number of comorbidities could cause additional problems that limited the frequency of therapy, and caused a decrease of QoL. ${ }^{16-18}$ Limitations of this study were cross sectional study, which is not analyzed about comorbidities factor, and the questionnaire filled by parents subjectively. Further study is necessary to analyze about comorbidities factor, and type of therapy specifically to determine the proper preventive and rehabilitative program of children with $\mathrm{CP}$.

\section{Conclusions}

The higher of parent's education level and frequency of therapy, the higher quality of life of children with CP. Further study need to analyze the correlation between comorbidities and therapy program specifically with PedsQoL.

\section{References}

1. Kuperminc MN, Stevenson RD. Growth and nutrition disorders in children with cerebral palsy. Dev Disabil Res Rev. 2008;14(2):137-46.

2. Vyas AG, Kori VK, Rajagopala S, Patel KS. Etiopathological study on cerebral palsy 
and its management by Shashtika Shali Pinda Sweda and Samvardhana Ghrita. Ayu. 2013;34(1):56-62.

3. Yeargin-Allsopp M, Braun KVN, Doernberg NS, Benedict RE, Kirby RS, Durkin MS. Prevalence of cerebral palsy in 8-year-old children in three areas of the United States in 2002: a multisite collaboration. J Pediatr. 2008;121(3):547-54.

4. Hullmann SE, Ryan JL, Ramsey RR, Chaney JM, Mullins LL. Measures of general pediatric quality of life: child health questionnaire (CHQ), DISABKIDS chronic generic measure (DCGM), KINDL-R, pediatric quality of life inventory (PedsQL) 4.0 generic core scales, and quality of my life questionnaire (QoML). J Arthritis Care Res. 2011;63(Sppl 11): S420-30.

5. Jewell AT, Stokes AI, Bartlett DJ. Correspondence of classifications between parents of children with cerebral palsy aged 2 to 6 years and therapists using the gross motor function classification system. J Dev Med Child Neurol. 2011;53(4):334-7.

6. Post MWM. Definitions of quality of life: what has happened and how to move on. Top Spinal Cord Inj Rehabil. 2014;20(3):16780.

7. World Health Organization. The world health report 2002: reducing risks, promoting healthy life. World Health Organization; 2002.

8. Boyle CA, Sheree B, Laura AS, Robin AC, Stephen J, Blumberg. Trends In The Prevalence Of Developmental Disabilities In Us Children, 1997-2008. J Pediatr.
2011;127(6):1034-42.

9. GlinacA, Tahirovic H.Family socioeconomic status and health-related quality of life in children with cerebral palsy: assesing differences between clinical and healthy samples. J Paediatr 2013;9(2):183-91.

10. Gong T, Lundholm C, Rejnö G, Mood C, Långström N, Almqvist C. Parental socioeconomic status, childhood asthma and medication use - a population-based study. PLoS One. 2014. Accessed Dec 5th 2017;9(9):Available from: https:// www.ncbi.nlm.nih.gov/pmc/articles/ PMC4154738/.

11. Brien IO, Duffy A, Shea EO. Medical futility in children's nursing: making end-of-life decisions. Br J Nurs. 2010;19(6):352-6.

12. Levesque JF, Harris MF, Russell G. Patientcentred access to health care: conceptualizing access at the interface of health systems and populations. Int J Equity Health. 2013. Accessed Dec 20 ${ }^{\text {th }}$ 2017;12(18):Available from: https://www.ncbi.nlm.nih.gov/pmc/ articles/PMC3610159/.

13. Kottke TE, Isham GJ. Measuring health care access and quality to improve health in populations. Prev Chronic Dis. 2010. Accessed Dec 20 2017;7(4): Available from: https://www.ncbi.nlm.nih.gov/pme/ articles/PMC2901571/.

14. Greitane A, Ceiciniece I, Cibule L, Teibe U, editors. Influence of accessibility of services on Quality of Life of school children with Cerebral Palsy in Latvia. SHS Web of Conferences; 2012: EDP Sciences.

15. Mishra K, Ramachandran S, Firdaus S, 
Rath B. The impact of pediatric nephrotic syndrome on parents' health-related quality of life and family functioning: An assessment made by the PedsQL 4.0 family impact module. SJDT. 2015;26(2):285-92.

16. Braveman P, Gottlieb L. The social determinants of health: it is time to consider the causes of the causes. Public Health Rep. 2014;129(Suppl 2):19-31.

17. Tessier D, Hefner J, Newmeyer A. Factors related to psychosocial quality of life for children with cerebral palsy. Int J Pediatr. 2014. Accessed Dec 20 2017;(1): Available from: https://www.hindawi.com/journals/ ijpedi/2014/204386/.
18. Safei I, Moeliono MA, Prabowo T. Loaded and unloaded sit-to-stand strengthening exercises effect to gross motor function measure in spastic diplegia cerebral palsy patients. IJIHS. 2016;4(1):8-14.

19. Varni JW, Burwinkle TM, Berrin SJ, Sherman SA, BA KA, Malcarne VL, et al. The PedsQL in pediatric cerebral palsy: reliability, validity, and sensitivity of the Generic Core Scales and Cerebral Palsy Module. J Dev Med Child Neurol. 2006;48(6):442-9. 